\title{
Effect of Snow, Temperature and Their Interaction on Highway Truck Traffic
}

\author{
Hyuk-Jae Roh ${ }^{1}$, Sandeep Datla ${ }^{2}$, Satish Sharma ${ }^{3^{*}}$ \\ ${ }^{1}$ Saskatchewan Ministry of Highways and Infrastructure, Regina, Canada \\ ${ }^{2}$ City of Edmonton, Edmonton, Canada \\ ${ }^{3}$ Faculty of Engineering, University of Regina, Regina, Canada \\ Email: jae.roh@gov.sk.ca, sandeep.datla@edmonton.ca, "Satish.Sharma@uregina.ca
}

Received October 23, 2012; revised November 24, 2012; accepted December 8, 2012

\begin{abstract}
Based on statistical amount of traffic and weather data sets from three weigh-in-motion sites for the study period of from 2005 to 2009, permanent traffic counters and weather stations in Alberta, Canada, an investigation is carried out to study impacts of winter weather on volume of passenger car and truck traffic. Multiple regression models are developed to relate truck and passenger car traffic variations to winter weather conditions. Statistical validity of study results are confirmed by using statistical tests of significance. Considerable reductions in passenger car and truck volumes can be expected with decrease in cold temperatures. Such reductions are higher for passenger cars as compared to trucks. Due to cold and snow interactions, the reduction in car and truck traffic volume due to cold temperature could intensify with a rise in the amount of snowfall. For passenger cars, weekends experience higher traffic reductions as compared to weekdays. However, the impact of weather on truck traffic is generally similar for weekdays and weekends. Interestingly, an increase in truck traffic during severe weather conditions is noticed at one of the study sites. Such phenomenon is found statistically significant. None of the past studies in the literature have presented the possibility of traffic volume increases on highways during adverse weather conditions; which could happen due to shift of traffic from parallel roads with inadequate winter maintenance programs. It is believed that the findings of this study can benefit highway agencies in developing such programs and policies as efficient monitoring of passenger car and truck traffic, and plan for efficient winter roadway maintenance programs.
\end{abstract}

Keywords: Highway Truck Traffic; Weigh-in-Motion; Traffic-Weather Models; Highway Design; Vehicle Classification; Highway Operations; Traffic Volume Studies; Transportation Statistics

\section{Introduction}

Traffic volumes on highways vary with both time and space. Temporal variation occurs with respect to hour, day and month of the year. The highway type, location and route choice behavior of road users cause spatial variation. Even if traffic streams are investigated for the same time and location, the variations of traffic volumes could differ substantially when each vehicle class travelling in the traffic stream is analyzed separately. Adverse weather conditions (in any season or climate) add another dimension to variations of traffic stream. Understanding of such temporal and spatial variations of truck and passenger car traffic under different weather conditions is very useful for both macroscopic and microscopic modelling of highway traffic.

Literature shows that extreme weather conditions cause travel disruptions resulting in slower speeds, travel delays, trip adjustments (for example, cancellation or de-

${ }^{*}$ Corresponding author. laying of trips) and increased collisions [1-11]. Owing to the geographical location, the winter weather conditions in Canada and many other northern regions in the World are very severe with heavy snowfall, and extremely cold temperatures. Such winter weather conditions cause increased travel disruptions and trip adjustments which could result in significant changes to truck and passenger car traffic patterns on highways. Datla and Sharma's $[1,12]$ study showed that winter weather causes variations in highway traffic volumes, and the magnitude of such variations depends on time of the day, day of the week, location, highway type and severity of the weather. However, their study and other similar studies in the literature were conducted solely on the basis of total traffic volume data which includes a mix of passenger cars and trucks. None of the past studies in the literature provided detailed information regarding impacts of winter weather on temporal and spatial variations of truck traffic. Impact of weather on route choice behavior of truck and passenger car drivers have also not been studied in the literature. 
More importantly, none of the studies in the literature has presented the possibility of traffic volume increases on high standard highways during adverse weather conditions; which could happen due to shift of traffic from low standard highways. This study is the first to recognize and model such occurrences.

The main purpose of this study is to investigate and model the impacts of winter weather on temporal and spatial variations of truck and passenger car traffic. Multiple regression models are developed to relate truck and passenger car traffic variations to winter weather conditions. This study uses Weigh-in-Motion (WIM) data from six different sites located on the highways of the province of Alberta, Canada. Hourly traffic volume data from several permanent traffic counters located in the vicinity of WIM stations have also been used in this study. Climate data is obtained from the 598 weather stations (operated by Environment Canada) in the province of Alberta. Modeling work is carried out using CARPACKAGE from the statistical software R $[13,14]$.

\section{Literature Review}

Past studies on the impact of weather on traffic flow can be broadly categorized into two groups: 1) studies focusing on the impact of weather on traffic parameters such as volume, speed, and headway and 2) studies focusing on the impact of weather events on the quality of traffic flow (e.g. operating level of service, crash rates, traffic delays, start-up delays at intersections, and traffic congestion). As the main focus of this study is on highway traffic volumes, most relevant studies in literature that deal with the impact of weather on highway traffic volumes are only presented in this section.

A majority of studies in literature reported quantitatively the association of traffic volumes with weather conditions i.e., magnitude of reduction in traffic volumes due to different weather conditions. Datla and Sharma [1, 12] studied the impact of cold and snow on daily and hourly traffic volumes on provincial highways of Alberta, Canada. Their study showed that the impact of cold and snow on traffic volumes vary with the day of the week, the hour of the day, the month of the year, the highway type, and the severity of cold temperature. They reported that average winter daily traffic volume reduces by about $30 \%$ during extremely cold weather (below $-25^{\circ} \mathrm{C}$ ). Their study also showed daily traffic volume reductions ranging from $7 \%$ to $17 \%$ for each centimeter of snowfall and up to $51 \%$ reduction during severe snowstorms (a snowfall of $30 \mathrm{~cm}$ or above). Effect of temperature and snowfall interactions on traffic volume was also investigated in their study. Hanbali and Kuemmel [3] studied the average traffic volume reductions due to snow storms on rural highways in the United States. They reported that traffic volume reductions up to 56\% might occur depending on the adversity of snow storm. For Lothian region, Scotland, Hassan and Barker [6] studied the association traffic with meteorological parameters such as minimum and maximum temperatures, snow and rain fall, snow on ground and sunshine hours were considered in their study. Their study concluded that the average traffic reductions were less than 5\% under extreme weather conditions but there was a reduction of $10 \%$ - $15 \%$ in traffic activity when snow was lying on the ground. Knapp and Smithson [2] analyzed the average traffic reductions on interstate highways in Iowa State during winter storms. Their study reported average reductions ranging from $16 \%$ to $47 \%$ for different storm events. They considered only the storm events having air temperature below freezing, wet pavement surface, pavement temperature below freezing and a snowfall of at least 4-h duration with intensity higher than $0.51 \mathrm{~cm} / \mathrm{h}$. Keay and Simmonds [8] reported the association of rainfall and other weather variables with traffic volume on urban arterials in Melbourne, Australia. The traffic reductions during wet days were $1.35 \%$ in winter and $2.11 \%$ in spring. A maximum reduction of $3.43 \%$ was reported for a rainfall ranging from $2 \mathrm{~mm}$ to $5 \mathrm{~mm}$ in spring. On Inter-state Highway 35 in northern rural Iowa, Maze et al. [9] reported a strong correlation between the percentage reduction in traffic volume and wind speed and visibility during snowy days. They have reported $20 \%$ reduction in traffic during snowy days with good visibility and low wind speed. The reductions are about $80 \%$ when the visibility is less than one-quarter mile and high wind speed (as high as 40 miles per hour). Changnon [15] studied the impact of variations in summer precipitation patterns on travel patterns in Chicago. Using the matched-pair technique, he compared the traffic volume patterns during the days with and without rainfall. Several other studies [3-5,7,10,16-19] have also reported reductions in traffic volume levels and changes in traffic patterns during adverse weather conditions.

Previous paragraph mainly discussed the impact of adverse weather conditions on traffic volumes without providing the details regarding travelers' decision-making behaviour before and during trips. In this section, some studies that consider driver behaviour that directly influence the temporal and spatial variation of highway traffic are reviewed. Hanbali and Kuemmel [3] indicated that the traveling characteristics of trip makers during adverse weather conditions depend on four factors: 1) the trip maker's willingness to travel; 2) the importance of the particular destination; 3) the difficulty of moving from the origin to the destination; and 4) other related factors. They indicated that a reduction in traffic movement occurs due to a traveler's desire to avoid travel during wet or snowy weather. Maki [20] reported that the 
traveling characteristics of trip makers are highly dependent on the severity of weather conditions and their driving comfort in adverse weather conditions. He mentioned that the driver behaviour during adverse weather conditions varies from place to place. He pointed out that traffic volume reductions occur during adverse weather conditions due to trip adjustments such as leaving for work early, staying late before coming back, and an avoidance of unnecessary and discretionary trips. Khattack [21] and ITT Industries [22] also reported that extreme weather conditions can cause drivers to change their mode of travel, route, departure time, or cancellation of the trip entirely. A recent survey conducted by Markku and Heikki [23] on driver behaviour during adverse weather conditions indicated that trip adjustments during these conditions could be associated with limited driving experience, increasing age, female gender, and the length of the trip. According to their survey, discretionary trips would be underrepresented on highways during poor driving conditions due to the cancellation or postponement of trips. Datla and Sharma [1] showed that the reduction in highway traffic volume due to snow and severe cold is related to the proportion of discretionary trips. Their study also indicted that social-recreational trip makers have more choices as to whether or not they will make a trip with respect to weather conditions. Datla and Sharma's study also showed more trip adjustments during the start of the winter season as compared to middle or end of winter season due to psychological adaptation of drivers to winter weather conditions.

As indicated previously, there is a serious lack of detailed information in the literature regarding impacts of winter weather on truck traffic. Differential impact of winter weather on passenger cars and trucks are not available in the existing literature. Also, there is little or no past research that investigated the interaction of the amount of snowfall and winter temperatures on passenger cars and truck traffic during severe winter conditions. Moreover, none of the studies in the literature have presented the possibility of traffic volume increases on high standard highways during adverse weather conditions; which could happen due to shift of traffic from parallel low standard highways with inadequate winter maintenance programs. Based on large traffic and weather data from weigh-in motion sites, permanent traffic counters and weather stations in the province of Alberta, a detailed investigation is carried in this study to address the research topics identified in this paragraph.

\section{Study Data}

Traffic data for this study were obtained from Alberta Transportation (AT), the agency that is responsible for provincial transportation in Alberta, Canada. They cur- rently operate nearly 350 permanent traffic counters (PTCs) to monitor traffic volumes on a 30,875-kilometer highway network. Each PTC represents a particular highway segment. The most recent data available at the start of this study were hourly traffic volume data for 16 years from year 1995 to 2010. AT also collects vehicle classification and weight data at six key highway sections using Weigh-in-Motion (WIM) sites. These WIM sites were installed in July 2004 and have continuously been collecting vehicle classification and load data for programs such as Alberta's Strategic Highway Research and Long Term Pavement Performance Programs. Calibration verification is conducted by a contractor on a monthly basis and it is at 79.4\% [24]. The weather data for this study were obtained from Environment Canada's National Climate Data and Information Archive [25]. Environment Canada collects climatologically data from nearly 8000 weather stations (including many intermittent ones) across the country. Each of these weather stations provide detailed weather parameters such as maximum, minimum, and mean temperature (measured in degrees centigrade $\left({ }^{\circ} \mathrm{C}\right)$ ), total rain (millimeters), total snow (centimeters), total precipitation (millimeters) and snow on ground (centimeters) on a daily basis. Details of raw data format and measuring methods for each of these weather parameters are available in Environment Canada website [25]. There were about 600 weather stations operated by Environment Canada in the province of Alberta.

Historically, the locations of WIM and PTC sites have been selected without considering the locations of weather stations in the province of Alberta. In some cases, weather stations are located close to the WIM or PTC site, and in other cases, they are far away. Therefore, one of the criteria used to select the study sites was based on the availability of weather stations within acceptable distance from the study sites. Literature review was carried out to define approximate distance within which weather conditions could be similar. From the research done by Andrey and Olley [19] and Datla and Sharma [1], it was found that weather conditions could be considered homogeneous within the area of 16 - $25 \mathrm{~km}$ radius around the weather station. A Geographical Information Systems (GIS) base map with 600 weather stations, 6 WIM sites and 350 PTC sites was developed. WIM and PTC sites with weather stations within the 16 - $25 \mathrm{~km}$ radius were identified using Proximity analysis module provided by GIS software Arc Map 9.9 [26].

Based on the availability of complete data from different data sources (WIM sites and weather stations), traffic and weather data from three WIM sites over a span of 5 years from 2005 to 2009 were selected for the present study.

After thorough research on different vehicle classifica- 
tion methods, Federal Highway Administration (FHWA) 13-category classification scheme was selected to classify the vehicles from WIM data. This scheme was developed in 1985 by Maine Department of Transportation (Maine DOT) [27] and is called "scheme F". This classification scheme is a standard scheme adopted by several highway agencies in North America.

Figure 1 shows location of study WIM sites and nearby Environment Canada weather stations. Two of the three study sites are located on Alberta Highway 2, which connects the province's two largest cities Edmonton and Calgary. One study site is located on Highway 2 just south of the City of Red Deer while the other is south of the City of Leduc. The third site is located on Highway 2A south of the City of Leduc. Highway 2 is the longest highway in Alberta. This corridor is among the top five in Canada in terms of traffic volume. The highway serves as the major economic corridor in western Canada, and it is part of the CANAMEX TRADE
CORRIDOR which connects Mexico to Alaska through Nevada, Utah, Montana, Alberta, British Columbia, and the Yukon. A significant portion of the heavy vehicle traffic on this facility is oil field related, such as preassembled oil processing equipment, pipes and construction machinery. Agricultural and consumer goods are the next significant goods movements on Highway 2.

The Calgary to Edmonton section of Highway 2 is a four lane divided freeway facility with a $110 \mathrm{~km} / \mathrm{hr}$ posted speed limit. Highway 2A parallels the east side of Highway 2 north of the City of Red Deer. Highway 2A is a two-lane undivided highway with varying speed limits. The posted speed limit on Highway 2A at the study site is $100 \mathrm{~km} / \mathrm{hr}$.

\section{Methodology}

To investigate the impact of weather on highway traffic by vehicle type, the raw data obtained from the WIM

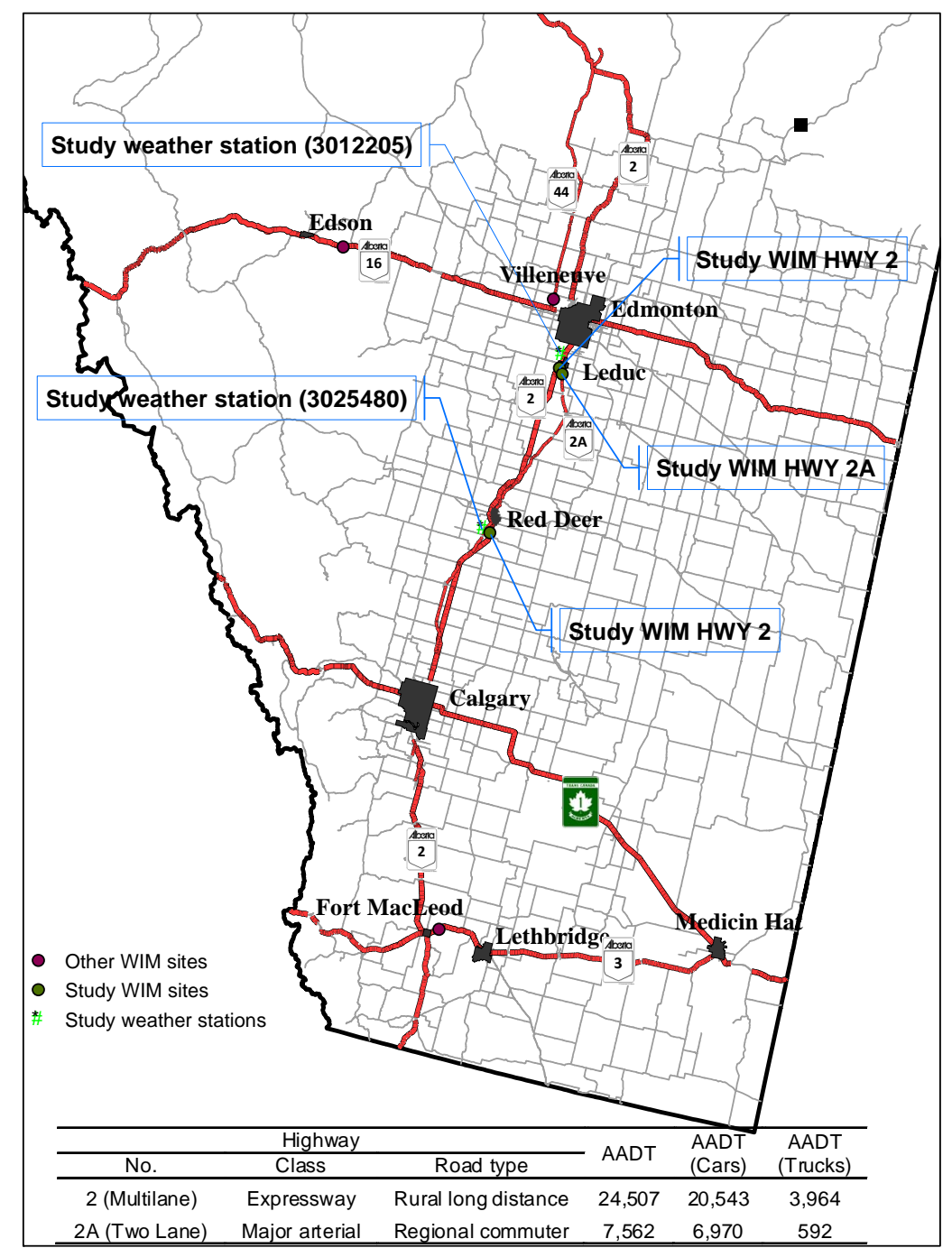

Figure 1. Thematic map showing cities in Alberta, study WIM site, weather station, and highway network. 
sites were classified using the FHWA classification method described in the previous section. This process resulted in 13 vehicle classes. However, due to lower number of total trucks in general and too many truck classes, sample data couldn't generate sufficient samples to carry out detailed statistical analysis by each vehicle class. Therefore, the 13 vehicle classes were aggregated into two classes i.e., passenger cars and trucks.

Historical weather records from Environment Canada climate database indicate that the province of Alberta experiences severe snowfall and cold conditions from November to March. Based on these observations study period for this research was limited to November to March from 2005 to 2009. Liu and Sharma [28] indicates that traffic patterns during long weekend holidays are very unique and special attention is needed to conduct research using data from holidays and their neighboring days. For this reason, the three holidays observed in the study period (New Year Day, Alberta Family Day (3rd Monday of February), and Christmas Day) were excluded from the study analysis.

A thorough analysis was carried out to understand the hourly, daily traffic patterns of the classified vehicles (trucks and passenger cars). Figure 2 shows the typical daily and hourly variations of total traffic, passenger cars and trucks at the three study sites during winter months. The typical weekday hourly volume to AADT ratios (hourly factors) are shown in Figures 2(a), (c) and (d). The typical daily traffic volume to AADT ratios (daily factors) versus day of week plots are shown in Figures 2(b), (d) and (f). Because major portion of total traffic is passenger cars (80\% to $85 \%$ ), the traffic patterns of total traffic and passenger cars are very similar. However truck patterns are unique and different to passenger car patterns. The hourly passenger car factor variations show a single peak from 5 PM to 7 PM for the highway 2 sites (Figure 2(a) and Figure 2(c)). For the highway 2A site two distinct peaks are observed each day (Figure 2(e)): the morning peak from $7 \mathrm{AM}$ to $9 \mathrm{AM}$ and the evening peak from $4 \mathrm{PM}$ to $7 \mathrm{PM}$. There is a general upward trend in weekday (Monday to Friday) passenger car traffic for all the study sites (see Figures 2(b), (d) and (f)). There is only a slight increase from Monday to Thursday; however, traffic on Friday traffic is substantially higher in all cases. The weekend passenger car traffic volumes are higher than the regular weekday (Monday to Thursday) passenger car traffic volumes and slightly less than Friday volumes for highway 2 sites (Figures 2(b) and (d)). For the highway 2A (Figure 2(f)), the Friday volumes are generally the highest, followed by Sunday, Saturday, and other weekdays. The differences in traffic patterns at the study sites show the need to conduct separate analysis. For trucks, the weekday hourly traffic patterns are different from passenger cars. Trucks show a single peak from $2 \mathrm{PM}$ to $6 \mathrm{PM}$. The daily truck volume patterns are also different as compared to passenger cars with weekday volumes significantly higher than weekends and unlike passenger cars, Friday volumes are similar to other weekdays. Also truck traffic decreases significantly (more than 50\%) during weekends as compared to weekdays. The traffic patterns in Figures 2(a) and (b) are very similar to the patterns in Figures 2(c) and (d). This indicates that the traffic conditions are very consistent on highway 2 with a similar traffic patterns for the two study sites located on highway 2. This is very helpful for testing the study findings for consistency. As per the road type classification system proposed by Sharma et al. [29] and traffic patterns observed in Figure 2, highway 2 sites can be classified as Regional Long Distance Roads and highway 2A site as a Commuter road. Because the traffic patterns for passenger cars and trucks are very distinct (as observed in Figure 2), modeling work has been carried out to develop separate models for the cars and trucks for Highway 2 and Highway 2A sites.

Literature indicates that a standard regression analysis is appropriate to quantify the association between highway traffic volumes and weather. For example, Keay and Simmonds [8] successfully used regression analysis to quantify the impact of rainfall on road traffic volume. Furthermore, Knapp and Smithson [2] showed the appropriateness of the relationship between traffic volume and total snowfall using regression analysis. Based on these previous successful experiences, regression models are developed in this study to relate passenger car and truck traffic volumes with temperature and snowfall.

It is a well known fact that highway traffic volumes generally follow a similar trend year after year. This is the reason why highway agencies across the World rely so much on historical data for applications such as imputation of missing data, traffic monitoring program plans, and development of daily, hourly and monthly adjustment factors. Therefore the expected traffic volume which is historical average traffic volumes at the same time and location is used as an independent variable in the model. Such average volumes represent the range of traffic volumes under different cold and snow conditions. Before proceeding to modeling, scatter plots were developed to get a better understanding of the relationship between dependent and independent variables identified for the modeling. The traffic volume factors (volume to AADT ratios) rather than traffic volumes (number of vehicles) were used in the analysis to account for yearly variations in traffic volumes. Although other weather factors (e.g., wind, pavement condition, etc.,) cause variations in daily traffic volume, we limited in this research to two weather factors (i.e., snow, and temperature) that commonly result severe driving conditions during winter season in North America. 
(a) Highway 2 (Red Deer)

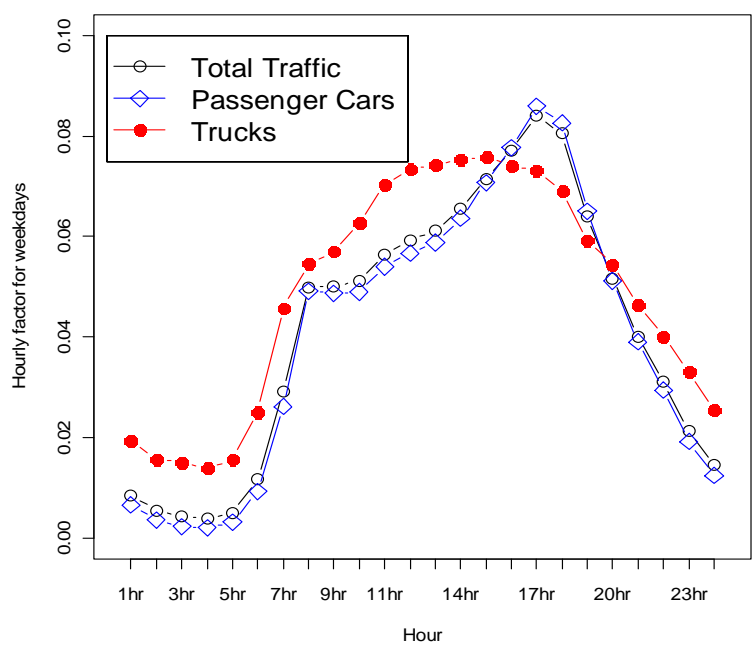

(c) Highway 2 (Leduc)

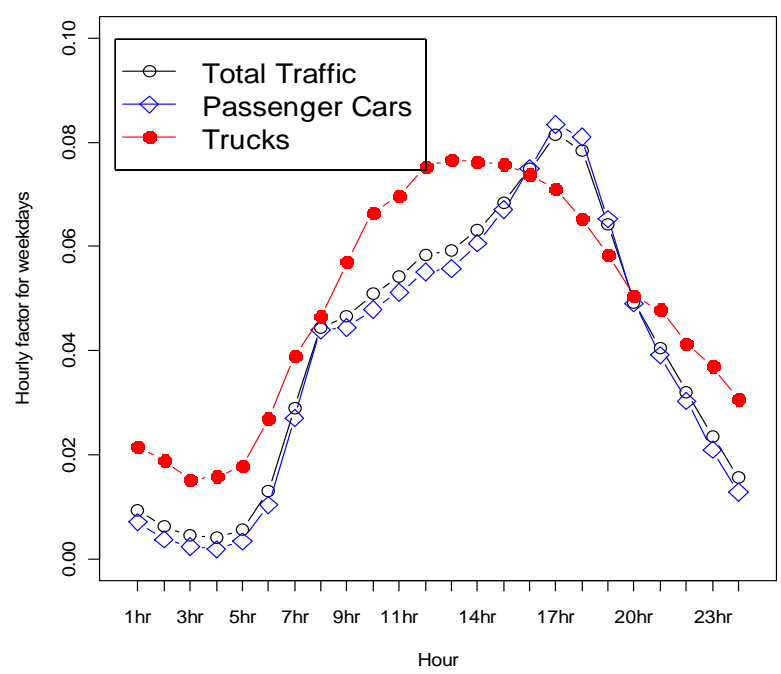

(e) Highway 2A (Leduc)

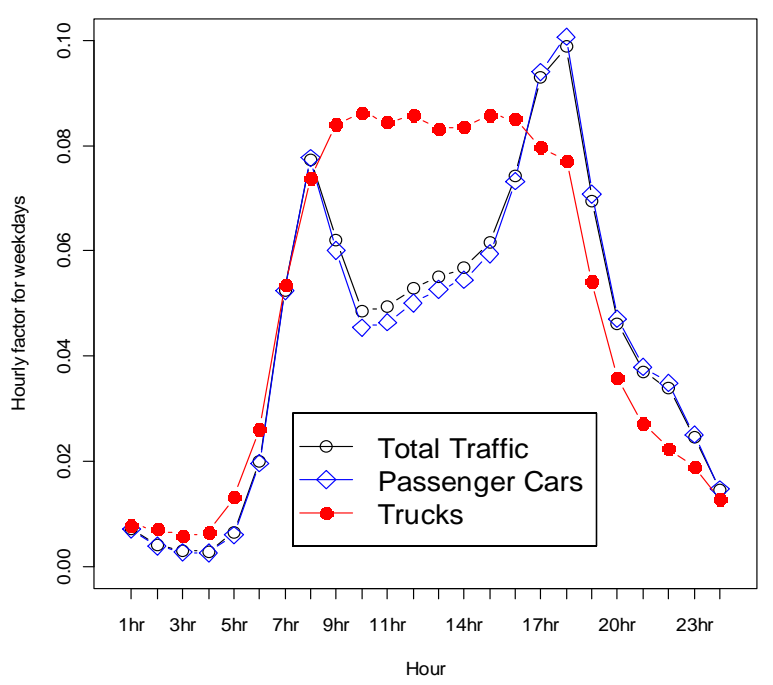

(b) Highway 2 (Red Deer)

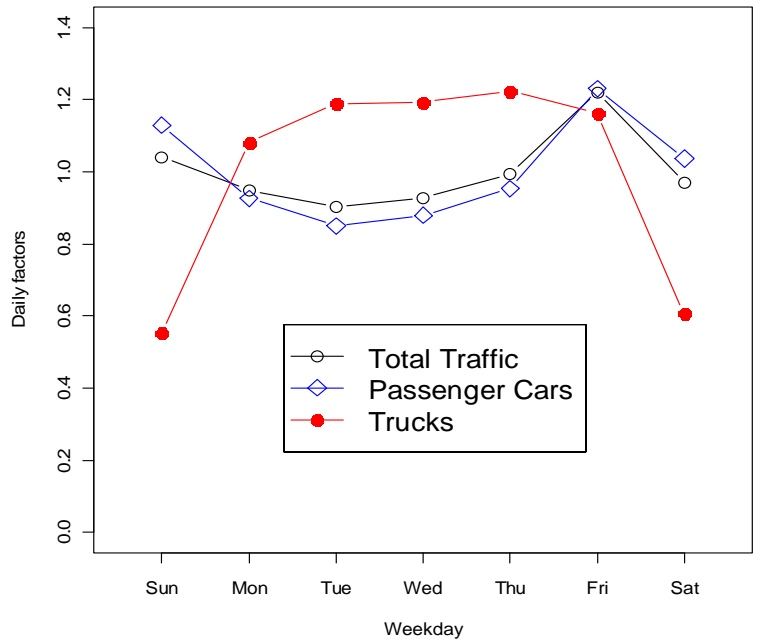

(d) Highway 2 (Leduc)

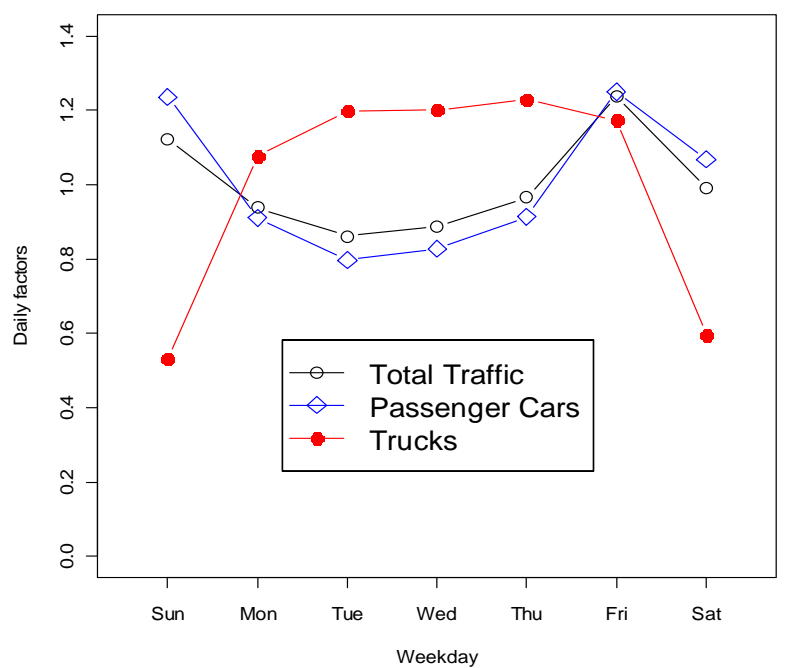

(f) Highway 2A (Leduc)

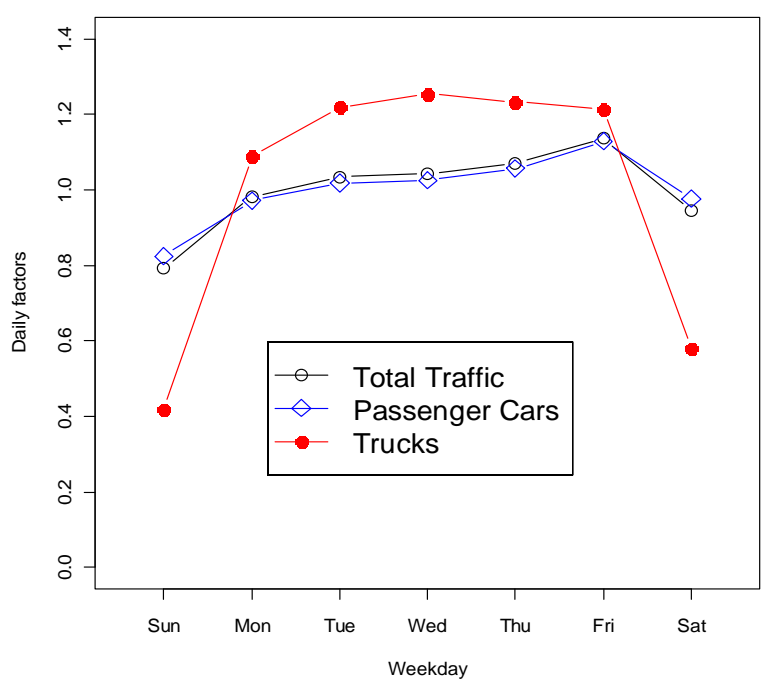

Figure 2. Typical daily and hourly variations of total traffic, passenger cars and trucks. 
Figures 3 and $\mathbf{4}$ show the scatter plots between car and truck traffic volume factors versus expected volume factors, snowfall and temperature. An estimated regression line is also added in the same plot to show the level of closeness between the two values. The blue circles in these plots represent weekdays and red squares represent weekends. The scatter plots between daily volume factors and expected daily volume factors show a very good cluster of sample data along the fitted regression line. This shows a strong positive linear relationship between daily volumes and historical average daily volumes (i.e. expected daily volume factor). The blue circles and red squares overlap considerably in case of total traffic and car traffic plots. For trucks, the red squares are always on the lower side as compared to blue circles. This is because of significantly lower truck traffic volumes on the weekends. It is worth noting that the weekday truck traffic factors are generally clustered between the values of 0.90 to 1.30 . However, the weekend daily truck factors were found to spread between 0.30 and 0.70 .

The regression lines of total vehicles and car volumes versus snowfall show moderate negative linear relationship,
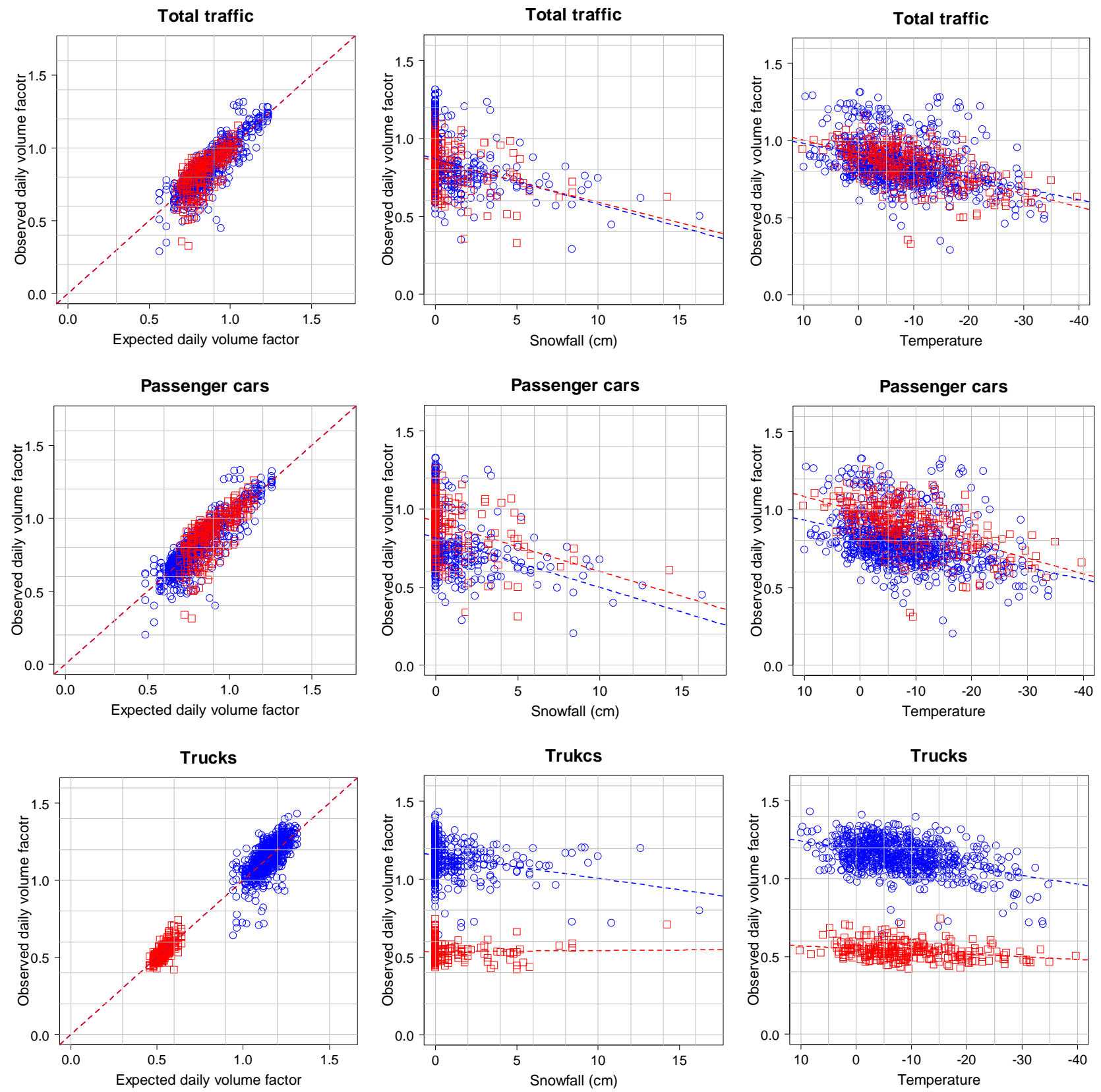

Figure 3. Scatter plots between car and truck traffic volume factors versus snowfall and temperature in highway 2 WIMs site (weekday traffic indicated by blue circle, weekend traffic by red square). 

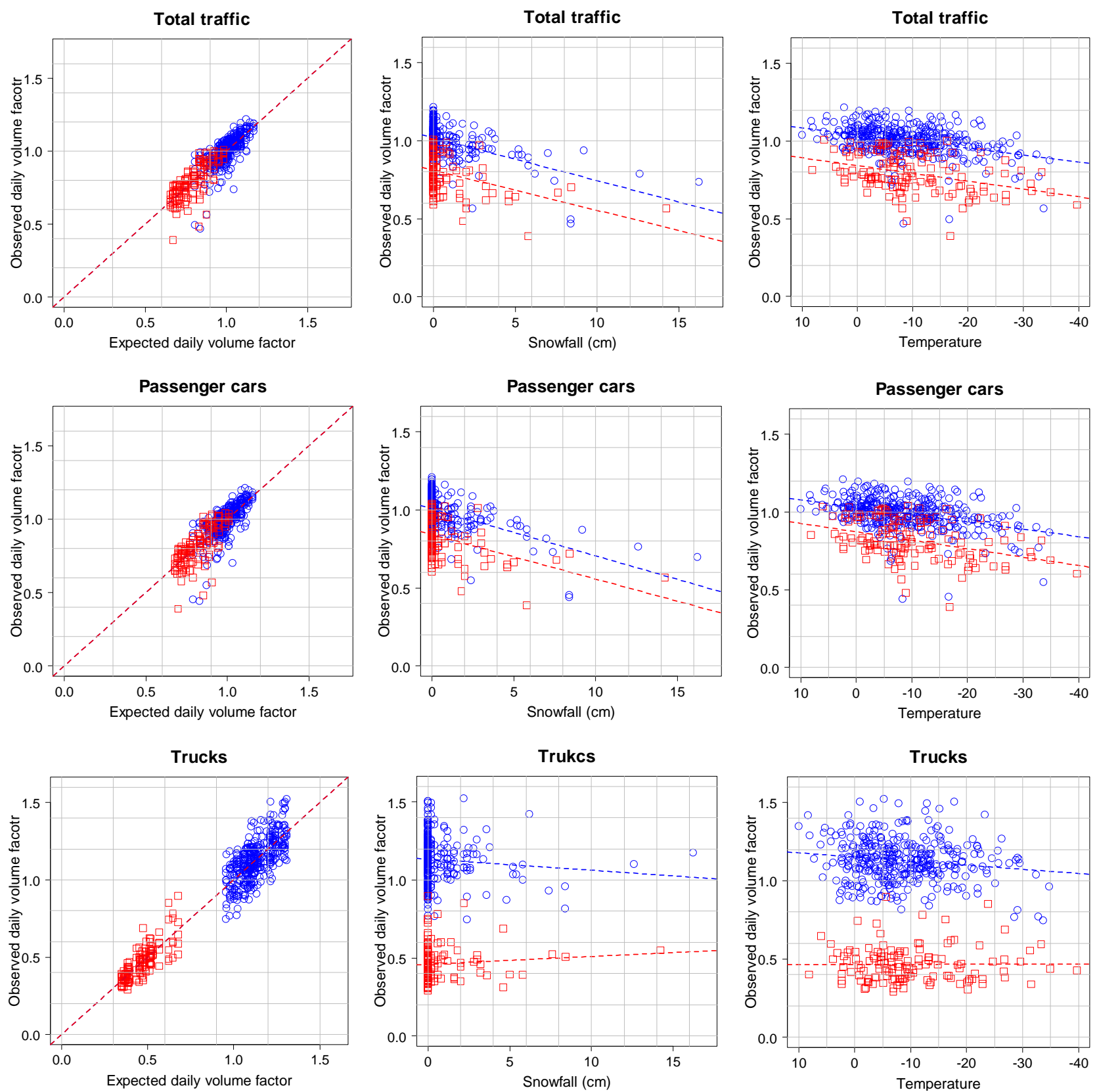

Figure 4. Scatter plots between car and truck traffic volume factors versus snowfall and temperature in highway $2 \mathrm{~A}$ WIM site (weekday traffic indicated by blue circle, weekend traffic by red square).

i.e., traffic volumes decrease with increase in amount of snowfall. A positive linear relationship is observed between daily volumes and temperature, i.e., daily passenger car volumes increase with increase in daily average temperature. The slope of regression lines of both snowfall and temperature plots are very similar between weekdays and Weekends. In the case of trucks, the clusters of observed data and the fitted regression lines follow similar very different as compared to cars. In case of trucks, the regression lines are very different for weekdays and weekends. Similar patterns are observed for the
Highway 2A site in Figure 4. These observations support the need for the development of separate models for cars and trucks. The differences in weekday and weekend scatter plots, especially for trucks, stresses development of separate models for weekdays and weekends.

The histograms of temperature for the days with snow and for the days without snow were constructed separately using weather data. The results indicated that average temperature is colder during the days with snowfall $\left(-10.94^{\circ} \mathrm{C}, 160\right.$ days over the five year period) than the no snowfall days $\left(-8.08^{\circ} \mathrm{C}, 350\right.$ days during the study 
period). A correlation analysis was also conducted between snowfall and temperature. The correlation coefficients ranged from 0.03 to -0.18 , which means that little to no correlation exists between snowfall and temperature. This observation justifies the inclusion of snow and cold as independent variables in model specification.

\section{Regression Model}

\subsection{Without Interaction of Snow and Temperature}

Regression analysis has long been recognized as a most flexible and widely used technique to explain variation of quantitative dependent variable by establishing the relationships between dependent variable and a specified set of independent variables in a form of additive and linear mathematical functions [30]. In this research, an attempt has been made to model the impact of weather factors on daily traffic volumes. For the purpose of initial mapping the relationships between daily traffic volume and weather factors, a regression model has been designed with three independent variables i.e., EDVF (expected daily volume factor), snow, and temperature. The additive regression model formulated for this research is:

$$
\begin{aligned}
y_{i}= & f(\text { expected daliy volume factor, } \\
& \text { snow fall, temperature }) \\
= & \beta_{1} \mathrm{EDVF}_{i}+\beta_{2} \mathrm{SNOW}_{i}+\beta_{2} \mathrm{TEMP}_{i}
\end{aligned}
$$

where,

$i$ : refers to the $i^{\text {th }}$ observation

$\beta_{1}, \beta_{2}, \beta_{3}$ : regression coefficients estimated for the respective independent variable

$y_{i}$ : estimated value of daily traffic volumes factor for different vehicle classes (cars, trucks etc.)

EDVF : expected daily volume factor

SNOW : amount of snowfall per day (cm)

TEMP : average daily temperature $\left({ }^{\circ} \mathrm{C}\right)$.

Normalized daily total volumes (traffic volume to AADT ratio), passenger car volumes (passenger car volume to passenger car AADT ratio), and truck traffic volume (truck volume to truck AADT ratio) are used instead of actual volumes to take into consideration the yearly variations in traffic volumes. The normal traffic volume and weekly traffic trends are reflected by adding an expected daily volume factor (EDVF) as an independent variable in model. EDVF is calculated using historical data of the same month, week, and day. The variables SNOW and TEMP represent the weather conditions.

\subsection{With Interaction of Snow and Temperature}

The additive regression model (Equation (1)) with EDVF, SNOW, and TEMP as independent variables would take into account the individual impact of cold and snowfall on highway traffic (i.e., the impact of temperature on traffic volumes after impact of snowfall is taken into account and the impact of each centimeter of snowfall after the effect of temperature is taken into account). A more complex model design is required to investigate whether the impact of snowfall on traffic volumes is the same at all temperature ranges or varies with the severity of temperature. Such analyses would verify the existence or non-existence of cold and snow interaction impacts on traffic volumes Therefore the model structure shown in Equation (1) is modified to accommodate interactions between cold (temperature) and snow. The differential impacts of snowfall by cold or, equivalently, the differential impacts of cold by snowfall were captured in the model by including $\mathrm{SNOW}_{i} * \mathrm{TEMP}_{i}$ interaction terms to the earlier model design in Equation (1). The final form of the model used in this paper is shown in Equation (2).

$$
\begin{aligned}
y_{i}= & f(\text { expected daliy volume factor, } \\
& \text { snow fall, temperature }) \\
= & \beta_{1} \mathrm{EDVF}_{i}+\beta_{2} \mathrm{SNOW}_{i}+\beta_{3} \mathrm{TEMP}_{i} \\
+ & \beta_{4} \mathrm{SNOW}_{i} * \mathrm{TEMP}_{i}
\end{aligned}
$$

where,

$\beta_{4}$ : regression coefficients estimated for the snowtemperature interaction variable.

Except interaction terms, all other terms serve the same purposes as defined in Equation (1).

\section{Results and Analysis}

The modeling process was carried out using the classified WIM data and corresponding weather records from the three study WIM sites (two WIMs site for highway 2 and one WIM site for highway 2A). Regression models were calibrated using Equation (2). In total, 18 models (2 study highway sites $\times 3$ day groups $\times 3$ vehicle classes) were developed. These include separate models for all days, weekdays and weekends and for total traffic, passenger cars and trucks for both highways. Table 1 shows the 18 calibrated models along with the statistical test results.

The overall goodness of fit of the regression model to sample data is evaluated by the squared multiple correlation coefficient $\left(R^{2}\right)$. The $R^{2}$ values for all models are over 0.98. The value of the $F$ test is also reported to assess the overall adequacy of the model. The results show that all the 18 models are statistically valid by rejecting the null hypothesis at better than the 0.001 level. The statistical significance for individual coefficients is evaluated by $t$-statistic. The significance levels of $t$-tests are shown in Table 1 using “*” symbol. More number of stars (“*”) represent better model. Incremental F-statistic 
and $R_{\text {Naive }}^{2}$ are also calculated to test the null hypothesis of no interaction between snow and cold and the test results are shown in Table 1.

Based on the results of the four statistical tests (i.e., $R^{2}, F$-test, incremental $F$-test, and $t$-test) conducted to evaluate the study models, it is apparent that the models fit well to the sample data and the structure of the proposed model is appropriate.

A partial effect analysis between the dependent variable and an independent variable could be determined by varying the selected independent variable between its lower and upper boundaries (based on the study samples) and holding the other independent variables at a certain value. The partial effects of cold temperatures on daily traffic volumes are investigated in this section i.e., for example, partial effect of cold temperatures on daily traffic for a specific pre-defined snowfall amount. Figures 5 and 6 show the graphs developed to study the partial impact of cold temperatures on car and truck volumes. Results are presented separately for weekdays and weekends.

The solid line gives estimated daily traffic from the models shown in Table 1. The dotted lines give the 95\% envelop for the upper and lower thresholds of dependent variable estimates. Each plot in Figures 5 and $\mathbf{6}$ shows the partial impact of cold temperatures on daily traffic

Table 1. Calibrated traffic weather models by vehicle class, day of the week and highway.

\begin{tabular}{|c|c|c|c|c|c|c|c|c|c|}
\hline \multirow[b]{2}{*}{ Variables } & \multicolumn{3}{|c|}{ All Days Models (Highway 2A) } & \multicolumn{3}{|c|}{ Weekdays Models (Highway 2A) } & \multicolumn{3}{|c|}{ Weekend Models (Highway 2A) } \\
\hline & $\begin{array}{l}\text { Total } \\
\text { Traffic }\end{array}$ & $\begin{array}{l}\text { Passenger } \\
\text { Cars }\end{array}$ & Trucks & $\begin{array}{l}\text { Total } \\
\text { Traffic }\end{array}$ & $\begin{array}{l}\text { Passenger } \\
\text { Cars }\end{array}$ & Trucks & $\begin{array}{l}\text { Total } \\
\text { Traffic }\end{array}$ & $\begin{array}{l}\text { Passenger } \\
\text { Cars }\end{array}$ & Trucks \\
\hline EDVF & $1.0329102^{* * *}$ & $1.0374549^{* * *}$ & $1.0010000^{* * *}$ & $1.0266381^{* * *}$ & $1.0309509^{* * *}$ & $1.0028914^{* * *}$ & $1.0605530^{* * *}$ & $1.0637035^{* * *}$ & $0.9907^{* * *}$ \\
\hline SNOW & $-0.0170572^{* * *}$ & $-0.0182616^{* * *}$ & $-0.0108900^{*}$ & $-0.0155569^{* * *}$ & $-0.0169710^{* * *}$ & -0.0085150 & $-0.0222481^{* * *}$ & $-0.0226961^{* * *}$ & $-0.11626^{* *}$ \\
\hline SNOWTEMP & $0.0004917^{*}$ & $0.0006044^{*}$ & $-0.0009029^{*}$ & $0.0006064^{*}$ & $0.0006976^{* *}$ & -0.0003994 & 0.0001235 & 0.0003061 & $-0.001941^{* * *}$ \\
\hline$R^{2}$ & 0.9971 & 0.9968 & 0.9916 & 0.9977 & 0.9974 & 0.9923 & 0.9952 & 0.9948 & 0.9823 \\
\hline Statistic & $43840^{* * *}$ & $39220^{* * *}$ & $14280^{* * *}$ & $39500^{* * *}$ & $35200^{* * *}$ & $11290^{* * *}$ & $6750^{* * *}$ & $6287^{* * *}$ & $1814^{* * *}$ \\
\hline $\begin{array}{c}\text { Change } \\
\text { from } R_{\text {Naive }}^{2}\end{array}$ & - & 0.0001 & 0.0001 & 0.0001 & 0.0001 & - & - & - & 0.0017 \\
\hline $\begin{array}{c}\text { Incremental } \\
\text { F-Statistic }\end{array}$ & - & $15.8125^{* * *}$ & $5.7857^{*}$ & $16.1304^{* * *}$ & $14.2692^{* * *}$ & - & - & - & $28.9220^{* * *}$ \\
\hline \multirow[t]{2}{*}{$\begin{array}{c}\text { Number of } \\
\text { Sample Days }\end{array}$} & 510 & 510 & 490 & 375 & 375 & 355 & 135 & 135 & 135 \\
\hline & \multicolumn{3}{|c|}{ All Days Models (Highway 2) } & \multicolumn{3}{|c|}{ Weekdays Models (Highway 2) } & \multicolumn{3}{|c|}{ Weekend Models (Highway 2) } \\
\hline Variables & Total Traffic & $\begin{array}{l}\text { Passenger } \\
\text { Cars }\end{array}$ & Trucks & $\begin{array}{l}\text { Total } \\
\text { Traffic }\end{array}$ & $\begin{array}{l}\text { Passenger } \\
\text { Cars }\end{array}$ & Trucks & $\begin{array}{l}\text { Total } \\
\text { Traffic }\end{array}$ & $\begin{array}{l}\text { Passenger } \\
\text { Cars }\end{array}$ & Trucks \\
\hline EDVF & $1.0419390^{* * *}$ & $1.0463226^{* * *}$ & $1.0160252^{* * *}$ & $1.0373627^{* * *}$ & $1.0405659^{* * *}$ & $1.0211869^{* * *}$ & $1.0558368^{* * *}$ & $1.0606082^{* * *}$ & $1.0085723^{* * *}$ \\
\hline SNOW & $-0.0125431^{* * *}$ & $-0.0135735^{* * *}$ & $-0.0052943^{*}$ & $-0.0144013^{* * *}$ & $-0.0153455^{* * *}$ & $-0.0080829^{* *}$ & -0.0078173 & -0.0102099 & 0.0051253 \\
\hline TEMP & $0.0028608^{* * *}$ & $0.0030388^{* * *}$ & $0.0015290^{* * *}$ & $0.0026138^{* * *}$ & $0.0026134^{* * *}$ & $0.0022545^{* * *}$ & $0.0035069^{* * *}$ & $0.0040640^{* * *}$ & 0.0004533 \\
\hline$R^{2}$ & 0.9949 & 0.9936 & 0.9962 & 0.9953 & 0.994 & 0.9964 & 0.994 & 0.993 & 0.9957 \\
\hline Statistic & $49690^{* * *}$ & $39670^{* * *}$ & $66770^{* * *}$ & $39520^{* * *}$ & $31070^{* * *}$ & $52080^{* * *}$ & $11030^{* * *}$ & $9497^{* * *}$ & $15520^{* * *}$ \\
\hline $\begin{array}{l}\text { Change } \\
\text { from } R_{\text {Naive }}^{2}\end{array}$ & 0.0001 & 0.0001 & - & 0.0001 & 0.0001 & - & 0.0003 & 0.0003 & 0.0001 \\
\hline $\begin{array}{c}\text { Incremental } \\
F \text {-Statistic }\end{array}$ & $19.92^{* * *}$ & $15.875^{* * * *}$ & - & $15.8723^{* * *}$ & $12.4333^{* * *}$ & - & $13.3^{* * *}$ & $11.4^{* * *}$ & $6.186^{*}$ \\
\hline $\begin{array}{l}\text { Number of } \\
\text { Sample Days }\end{array}$ & 1020 & 1020 & 1020 & 750 & 750 & 750 & 270 & 270 & 270 \\
\hline
\end{tabular}

${ }^{* * *}$ Coefficient is statistically significant at the 0.001 level; ${ }^{* *} 0.01$ level; ${ }^{*} 0.05$ level. 
volumes for a specific combination of vehicle type, day of the week, location and pre-defined amount of snowfall. First row of plots in Figure 5 show the change in daily volume factor of passenger cars due to winter temperatures during weekdays for the Highway 2 sites for different pre-defined amounts of snowfall. These plots are generated by fixing EDVF at its average value calculated from sample data set. It should be noted that the estimated daily volume factor at the point where the two dotted lines cross each other shows the average EDVF for that particular subset of data. Also note that the
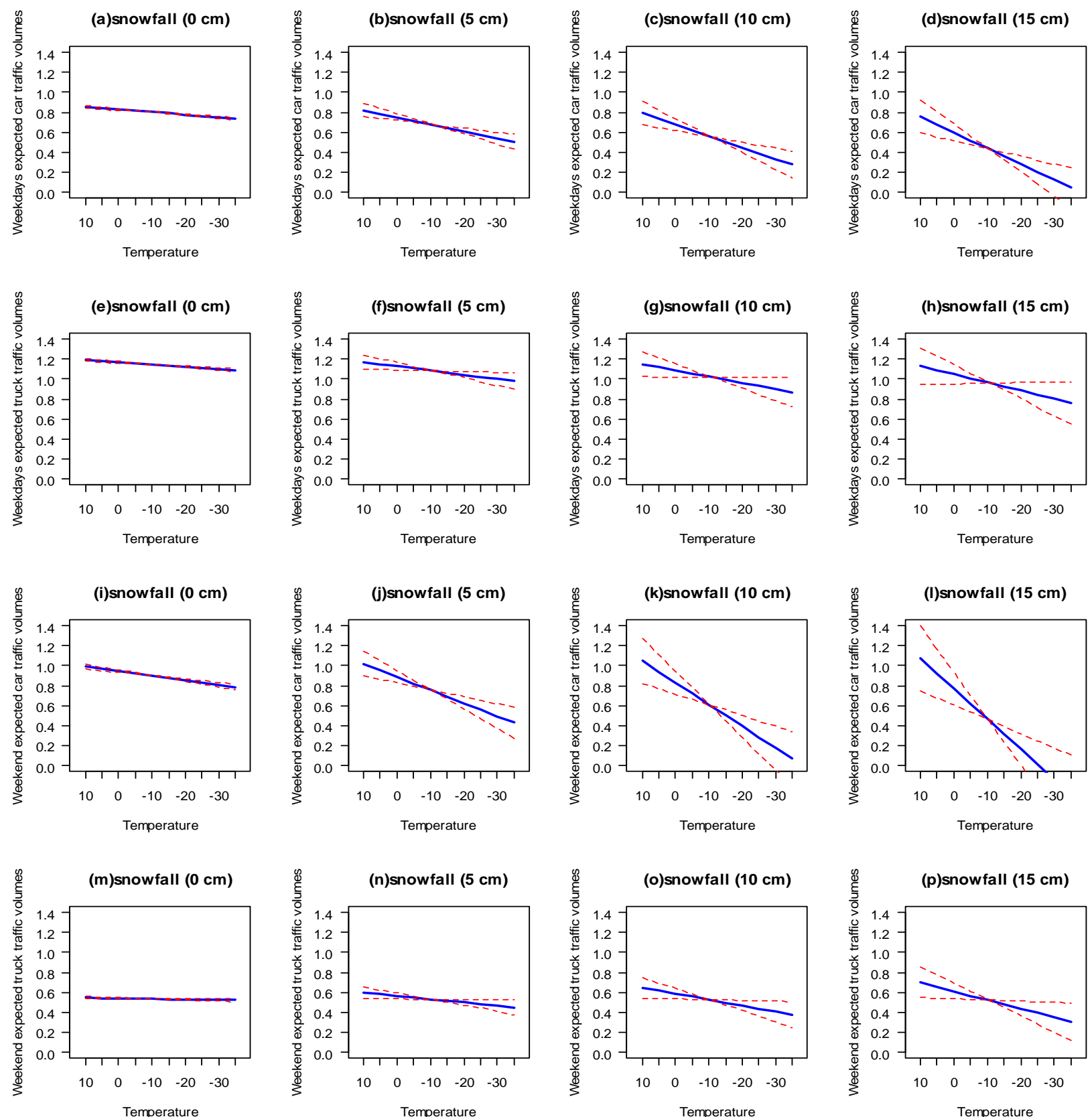

Figure 5. Partial impact of cold temperatures and snowfall on car and truck volumes for highway 2 sites (95\% envelopes of volume estimates indicated by red dotted line, expected volume by blue solid line). 

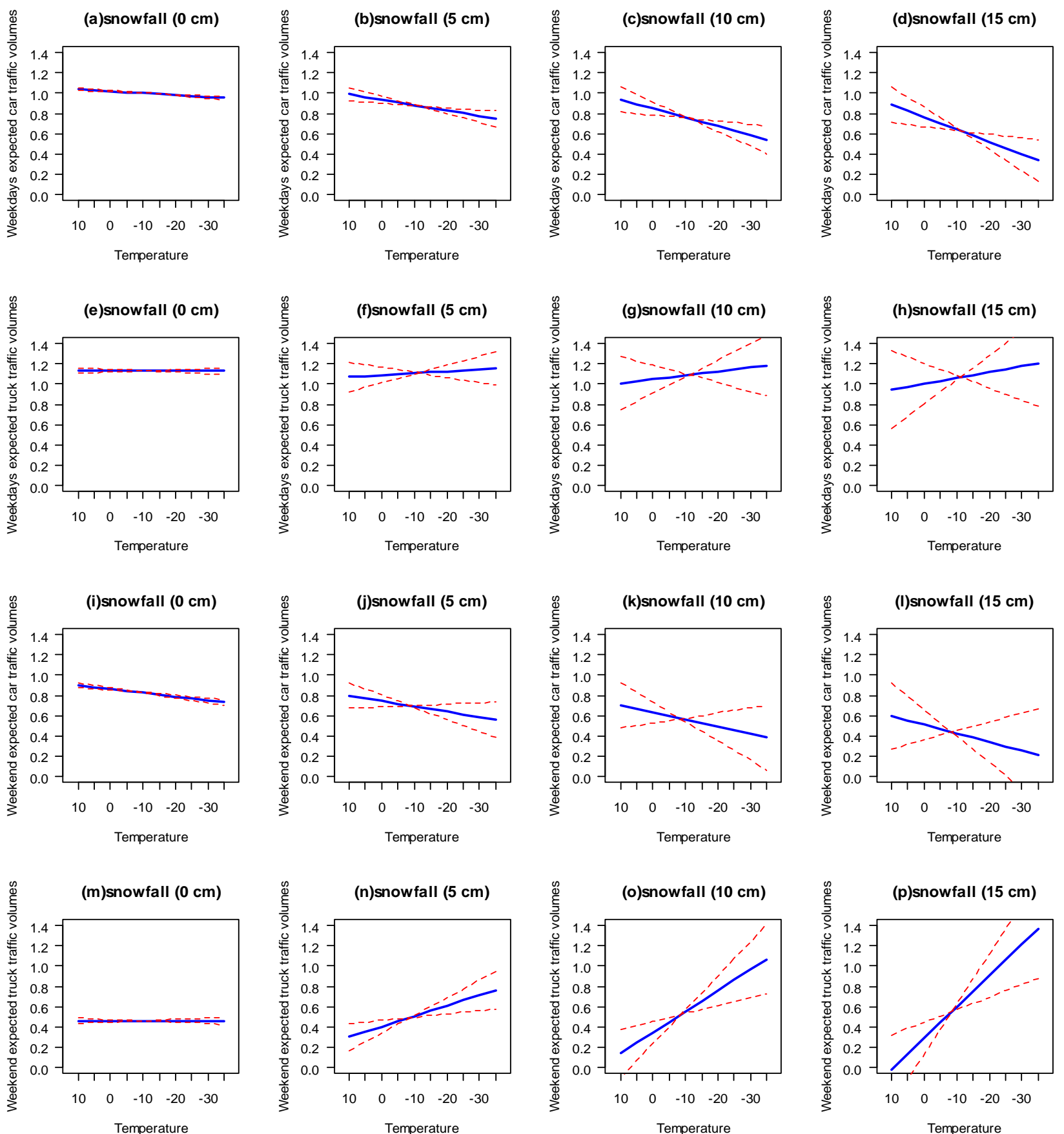

Figure 6. Partial impact of cold temperatures and snowfall on car and truck volumes for highway 2 A Site (95\% envelopes of volume estimates indicated by red dotted line, expected volume by blue solid line).

(Highway 2A site).

Based on the traffic weather patterns of Figure 5, the following interpretations can be made for Highway 2 sites, which serve regional long distance trips:

- There is a clear indication that traffic volume on a given day depends on severity of cold and amount of snowfall.

- A reduction in passenger car and truck volumes can be expected with increase in severity of cold tem- peratures. The amount of decrease in traffic volume depends on severity of cold.

- When there is no snowfall the impact of cold temperature on both car and truck volumes is very marginal (see plots in Figures 5(a), (e), (i) and (m)).

- As the amount of snowfall increases the steepness of the regression lines increases, which means that the reduction in traffic volume due to cold temperature would intensify with a rise in amount of snowfall. 
This clearly shows the existence of cold and snowfall interactions.

- A snowfall of $15 \mathrm{~cm}$ or higher during severe cold conditions $\left(-20^{\circ} \mathrm{C}\right.$ or lower) would result in a dramatic decrease in passenger car traffic on the road (see plots in Figures 5(d) and (l)).

- With higher amounts of snowfall, passenger cars experience higher reductions due to cold and snowfall as compared to trucks (as shown in plots $d$ and $l$ for cars; and plots $\mathrm{h}$ and $\mathrm{p}$ for trucks)

- For passenger cars, the weekend plots (Figures 5(i), (j), (k) and (l)) are steeper than weekdays (a, b, c, and d) indicating higher car traffic reductions in weekends as compared to weekdays. In the case of trucks, the regression lines seem parallel, which means the impact of cold and snow on truck traffic is similar for weekdays and weekends.

- It should be noted that the width of the 95\% envelop (shown by dashed lines) also increases from left to right indicting that the reliability of model estimate deplete with increase in severity of weather conditions. This could be because of low sample size due to lesser number of days of heavy snowfall during the winter season.

The amount of reduction in traffic volume may be attributed to the proportion of discretionary trips in the traffic stream. The existence of more discretionary trips results in higher trip adjustments and, hence, higher traffic reductions. The reason of higher weekend traffic reductions may be due to the large proportion of discretionary trips during weekends. Trucks (or commercial vehicles) are usually required to follow rigid schedules to complete their mandatory travel irrespective of severe weather conditions. These kinds of business-oriented mandatory movements are most likely to generate unique truck travel patterns even when weather is unfavorable for making a trip. This could be the reason for (i) lower truck reductions in general and (ii) similar impact of weather on weekdays and weekends truck traffic

Figure 6 shows the partial impact of cold on car and truck traffic on Highway 2A site, which serves as a regional commuter road in Leduc region. Interpretation of plots is the same as in Figure 5. Similar to Highway 2, passenger car traffic experiences reduction in volume with increase in severity of cold and amount of snowfall. However, for both weekdays and weekends, the regression lines seem to be less steep than those observed for Highway 2. This indicates lesser impact of cold on car traffic at Highway 2A site as compared to Highway 2. It is interesting to note that the width of the 95\% envelops of volume estimates for Highway 2A site are larger as compared to the plots in Figure 5, especially for weekend car traffic. This could be due to a much smaller sample size available for used in the analysis for Highway
2A site, as shown in Table 1. Except for these differences, all the remaining observations made earlier based on passenger car traffic-weather relation plots in Figure 5 are valid for Highway 2A site also.

The behavior of truck traffic at Highway 2A site during adverse weather conditions is quite different from the Highway 2 site. It is very interesting to see the regression lines of truck traffic showing a reverse trend i.e., increase in truck traffic volume with increase in severity of weather conditions. Such an increase in truck traffic is marginal for weekdays and high for weekends. This is contradictory to what has been observed for truck traffic at Highway 2 site. Moreover, none of the studies in the literature reported increase in traffic volumes during severe weather conditions. A further investigation was conducted to understand the possible reasons for such a controversial truck traffic patterns.

After reviewing the highway network near the study site, it was found that Highway 814 runs parallel to the Highway 2A. Highway 814 is a secondary highway with lower priority for winter road maintenance (snow removal etc.). Therefore it is possible that truck drivers may change their travel route by shifting to Highway 2A. A careful analysis of hourly traffic data from permanent traffic counter site located on Highway 814 showed significantly lower traffic volumes during the days with severe weather conditions (i.e., higher than normal traffic reductions that were seen at other similar highway segments). Brief communications with local municipalities in the vicinity of the study sites also indicated the possibility of traffic shifting. Therefore it could be concluded that there is a possibility of traffic volume increases on high standard highways during adverse weather conditions, which could happen due to shift of traffic from parallel low standard highways.

\section{Summary and Conclusions}

The literature study presented in this paper indicates clearly that severe weather conditions trigger variations in highway traffic. However, none of the past studies in the literature provided detailed information regarding impacts of winter weather on temporal and spatial variations of truck traffic. It is believed that understanding of truck traffic variations (or behaviour) under severe weather conditions can benefit highway agencies in developing such programs and policies as efficient monitoring of passenger car and truck traffic, and plan for efficient winter roadway maintenance programs.

An attempt has been made in this study to quantify the traffic variations under different weather conditions. Vehicle classification data from the WIM sites operated in the province of Alberta were used in this study. Climate data (2 weather stations) were obtained from the 598 
weather stations (operated by Environment Canada) in the province of Alberta. Multiple regression models were formulated and calibrated to relate truck and passenger car traffic variations to winter weather conditions. All the calibrated models were tested for statistical significance of the independent variables using the standard test statistics such as $F$-test, incremental $F$-test, and $t$-test.

A number of conclusions were drawn from the study results. Firstly, both car and truck traffic volumes on highways vary with severity of cold and amount of snowfall. The impact of cold temperature on both car and truck volumes is marginal during no snowfall days. The reduction in traffic volume due to cold temperature would intensify with a rise in amount of snowfall indicating the existence of cold and snowfall interactions. With higher amounts of snowfall, passenger cars experience higher reductions due to cold and snowfall as compared to trucks. A snowfall of $15 \mathrm{~cm}$ or higher during severe cold conditions $\left(-20^{\circ} \mathrm{C}\right.$ or lower) would result in very few Cars travelling on the road. Moreover passenger cars experience higher traffic reductions in weekends as compared to weekdays. In the case of trucks the impact of cold and snow on truck traffic is similar for weekdays and weekends.

It is evident from this study that passenger cars are more vulnerable to adverse weather conditions than trucks. This vulnerability to severe weather conditions could be attributed to such behavior of drivers as choosing flexible departure times, changing routes, or canceling travel entirely and being able to make trip adjustments by avoiding discretionary trips. Trucks are not as greatly affected as passenger cars by adverse weather conditions. Trucks (or commercial vehicles) are usually required to follow rigid schedules to complete their mandatory travel irrespective of severe weather conditions. These kinds of business-oriented mandatory movements are most likely to generate unique truck travel patterns even when weather is unfavorable for making a trip.

Interestingly, the modelling results for one of the study sites reveal that higher truck traffic volumes can result during heavy snowfall (or other adverse weather conditions) in winter months. This is contradictory to observations from other similar studies in the literature. None of the studies in literature have reported such an increase in traffic volumes during severe weather conditions. A further investigation carried out for this study to understand the reasons for such behavior indicated shifting of trucks from secondary highways to primary highways due to poor winter maintenance programs. Therefore it can be concluded that there is a possibility of traffic volume increases on high standard highways during adverse weather conditions; which could happen due to shift of traffic from parallel low standard highways.

\section{Acknowledgements}

The authors are grateful towards the Natural Science and Engineering Research Council of Canada (NSERC), the Faculty of Graduate Studies at the University of Regina, and Saskatchewan Government Insurance (SGI) for their financial support. The authors also thank Alberta Infrastructure and Transportation for providing the WIM data used in this study.

\section{REFERENCES}

[1] S. Datla and S. Sharma, "Variation of Impact of Cold Temperature and Snowfall and Their Interaction on Traffic Volume," In: Transportation Research Record: Journal of the Transportation Research Board, No. 2169, Transportation Research Board of the National Academies, Washington DC, 2010, pp. 107-115.

[2] K. K. Knapp and L. D. Smithson, "Winter Storm Event Volume Impact Analysis Using Multiple-Source Archived Monitoring Data,” In: Transportation Research Record: Journal of the Transportation Research Board, No. 1700, Transportation Research Board of the National Academies, Washington DC, 2000, pp. 10-16.

[3] R. M. Hanbali and D. A. Kuemmel, "Traffic Volume Reduction Due to Winter Storm Conditions,” In: Transportation Research Record: Journal of the Transportation Research Board, No. 1387, Transportation Research Board of the National Academies, Washington DC, 1993, pp. 159-164.

[4] L. C. Goodwin, "Weather Impacts on Aterial Traffic Flow,” The Road Weather Management Program, FHWA, US Department of Transportation, Washington DC, 2002.

[5] F. L. Hall and D. Barrow, "Effects of Weather and the Relationship between Flow and Occupancy on Freeways,” In: Transportation Research Record: Journal of the Transportation Research Board, No. 1194, Transportation Research Board of the National Academies, Washington DC, 1988, pp. 55-63.

[6] Y. A. Hassan and J. J. Barker, "The Impact of Unseasonable or Extreme Weather on Traffic Activity within Lothian Region, Scotland,” Journal of Transport Geography, Vol. 7, No. 3, 1999, pp. 209-213. doi:10.1016/S0966-6923(98)00047-7

[7] A. T. Ibrahim and F. L. Hall, "Effect of Adverse Weather Conditions on Speed-Flow-Occupancy Relationships,” In: Transportation Research Record: Journal of the Transportation Research Board, No. 1457, Transportation Research Board of the National Academies, Washington DC, 1994, pp. 184-191.

[8] K. Keay and I. Simmonds, "The Association of Rainfall and Other Weather Variables with Road Traffic Volume in Melbourne, Australia,” Accident Analysis and Prevention, Vol. 37, No. 1, 2005, pp. 109-124. doi:10.1016/j.aap.2004.07.005

[9] T. H. Maze, M. Agarwal and G. D. Burchett, "Whether Weather Matters to Traffic Demand, Traffic Safety, and Traffic Operations and Flow," In: Transportation Research Record: Journal of the Transportation Research 
Board, No. 1948, Transportation Research Board of the National Academies, Washington DC, 2006, pp. 170-176.

[10] B. L. Smith, K. G. Byrne, R. B. Copperman, S. M. Hennessy and N. J. Goodall, "An Investigation into the Impact of Rainfall on Freeway Traffic Flow," Proceedings of the Annual Meeting of the Transportation Research Board, Washington DC, 2004.

[11] J. Andrey, B. Mills, M. Leahy and J. Suggett, "Weather as a Chronic Hazard for Road Transportation in Canadian Cities," Natural Hazards, Vol. 28, No. 3, 2003, pp. 319343. doi:10.1023/A:1022934225431

[12] S. Datla and S. Sharma, "Impact of Cold and Snow on Temporal and Spatial Variations of Highway Traffic Volumes,” Journal of Transport Geography, Vol. 16, No. 5, 2008, pp. 358-372. doi:10.1016/j.jtrangeo.2007.12.003

[13] J. Fox, “An R Companion to Applied Regression,” SAGE Publications, Inc., Thousand Oaks, 2011.

[14] R Foundation for Statistical Computing, " $\mathrm{R}$ Development Core Team: A Language and Environment for Statistical Computing,” R Foundation for Statistical Computing, Vienna, 2010.

[15] S. A. Changnon, "Effects of Summer Precipitation on Urban Transportation,” Climatic Change, Vol. 32, No. 4, 1996, pp. 481-495. doi:10.1007/BF00140357

[16] J. C. McBride, M. C. Benlangie, W. J. Kennedy, F. R. McCornkie, R. M. Steward, C. C. Sy and J. H. Thuet, "Economic Impacts of Highway Snow and Ice Control," FHWA, US Department of Transportation, Washington DC, 1997.

[17] V. P. Shah, A. D. Stern, L. C. Goodwin and P. Pisano, "Analysis of Weather Impacts on Traffic Flow in Metropolitan Washington DC," Proceedings of the Annual Meeting of Institute of Transportation Engineers, Washington DC, 2003.

[18] L. I. Zang, P. Holm and J. Colyar, "Identifying and Assessing Key Weather-Related Parameters and Their Impact on Traffic Operations Using Simulation,” FHWA, US Department of Transportation, Washington DC, 2004.

[19] J. Andrey and R. Olley, "Relationships between Weather and Road Safety, Past and Future Directions," Climatological Bulletin, Vol. 24, No. 3, 1990, pp. 123-137.

[20] P. J. Maki, “Adverse Weather Traffic Signal Timing,” Proceedings of the Annual Meeting of Institute of Transportation Engineers, Las Vegas, 1999.

[21] A. J. Khattak, P. Kantor and F. M. Council, "Role of Ad- verse Weather in Key Crash Types on Limited Access Roadway-Implications for Advanced Weather System," In: Transportation Research Record: Journal of the Transportation Research Board, No. 1621, Transportation Research Board of the National Academies, Washington DC, 1998, pp. 10-19.

[22] ITT Industries, Inc., System Division, "Identifying and Assessing Key Weather-Related Parameters and Their Impacts on Traffic Operations Using Simulation,” FHWA, US Department of Transportation, Washington DC, 2003.

[23] M. Kilpeläinen and H. Summala, "Effects of Weather and Weather Forecasts on Driver Behavior," Transportation Research Part F: Traffic Psychology and Behaviour, Vol.10, No. 4, 2007, pp. 288-299. doi:10.1016/j.trf.2006.11.002

[24] P. Kilburn, “Alberta Infrastructure \& Transportation Weigh in Motion Report," Government of Alberta Ministry of Transportation, Calgary, 2008.

[25] Weather Office, Environment Canada, Gatineau, Quebec, Canada, 2010.

www.climate.weatheroffice.gc.ca/climateData/canada_e.h tml.

[26] “ArcGIS 10 Help Library: Geographic Information System (GIS),” ArcGIS 10, Environmental System Research Institute, Inc., Redlands, 2010.

[27] J. H. Wyman, G. A. Braley and R. I. Stephens, "Field Evaluation of FHWA Vehicle Classification Categories," FHWA, US Department of Transportation, Washington DC, 1985.

[28] Z. B., Liu and S. Sharma, "Statistical Investigations of Statutory Holiday Effects on Traffic Volumes,” In: Transportation Research Record: Journal of the Transportation Research Board, No. 1945, Transportation Research Board of the National Academies, Washington DC, 2006, pp. 40-48.

[29] S. Sharma and A. Werner, "Improved Method of Grouping Province Wide Permanent Traffic Counters," In: Transportation Research Record: Journal of the Transportation Research Board, No. 815, Transportation Research Board of the National Academies, Washington DC, 1981, pp. 12-18.

[30] J. Fox, “Applied Regression Analysis and Generalized Linear Models,” SAGE, Inc., Thousand Oaks, 2008. 